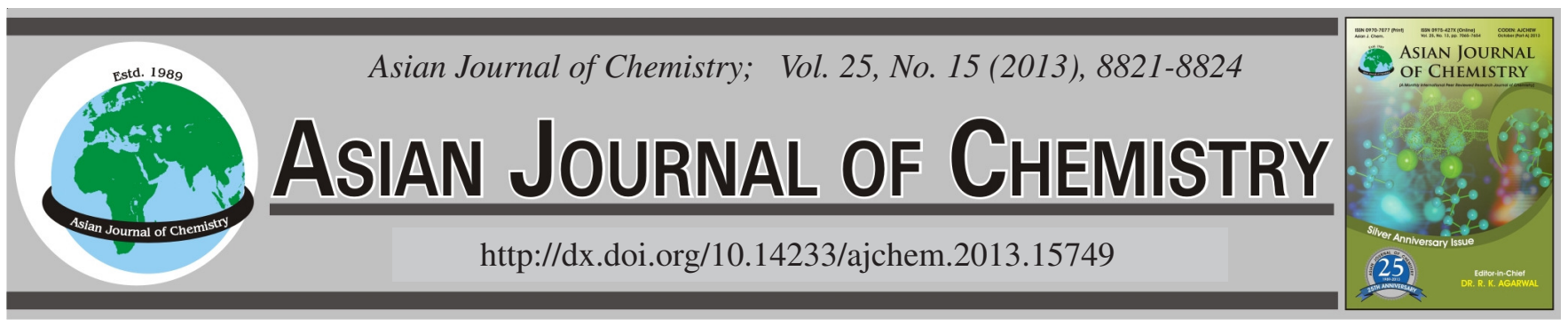

\title{
Depyrogenation Mechanism of Baicalin Solution with Activated Carbon
}

\author{
X.L. ZHi, C.Y. Li, H.Y. Li and G.P. PENG*
}

Department of Pharmaceutical engineering, Pharmacy College, Nanjing University of Chinese Medicine, Nanjing City, China

*Corresponding author: Tel./Fax: +86 25 86798186; E-mail: guopingpeng@ sohu.com

(Received: 9 May 2013;

Accepted: 30 August 2013)

AJC-14056

\begin{abstract}
In clinical practice, traditional Chinese medicine injections with the function of clearing away heat and toxic materials tend to cause pyrogen reaction. The pyrogen removal experiments showed that the activated carbon had the defection of applicability, especially in injections containing baicalin. To simulate a sudden pyrogen contamination in injections, the bacterial endotoxin indicator was added into aqueous solution of baicalin. As the activated carbon dosage increasing, a plateau of removal efficiency appeared, in which the removal efficiency of bacterial endotoxin was not significantly improved. However, the loss of baicalin was markedly increased. Besides, the comparison between two kinds of manufacturing techniques of traditional Chinese medicine injections containing baicalin showed that competitive adsorption existed between bacterial endotoxin and baicalin. Therefore, during the injection production, interactions among manufacturing techniques, compositions and harmful substances should be definitely clear, which makes a far-reaching significance on the quality promotion of injections.
\end{abstract}

Key Words: Bacterial endotoxin, Activated carbon, Ultrafiltration, Traditional Chinese medicine.

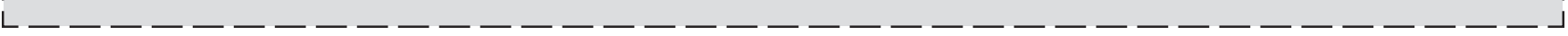

\section{INTRODUCTION}

In recent years, the safety of traditional Chinese medicine injections has attracted a lot of concern and the pyrogen (also known as bacterial endotoxin ${ }^{1-3}$ ) reaction is one of the most common adverse reactions. Since injections directly enter the blood, medical negligence caused by pyrogen reaction ${ }^{4-7}$ happens every year, bringing a lot of troubles to patients, enterprises and society. Nowadays the primary method of removing bacterial endotoxin in drugs is activated carbon adsorption $^{1,8,9}$, so does in injection. However, the activated carbon has its limitations on the adsorption of bacterial endotoxin. During the manufacturing progress of pyrogen removal from traditional Chinese medicine injections, it was found that activated carbon saturated adsorption may not be the only reason for pyrogen overdose.

As a commonly-used adsorbent, activated carbon mainly depends on VDW (van der Waals') force of long-carbon chain to absorb and retain composition in refined handling on polysaccharides and some macromolecules. Bcause of lipopolysaccharide structures of bacterial endotoxin, activated carbon has a good adsorption effect and the adsorption characteristics are not exclusive. Traditional Chinese medicine injections with the function of clearing away heat and toxic materials are commonly used in clinic and because of this function, rabbit experiments cannot accurately judge the effect of bacterial endotoxin-removal with activated carbon.
In this paper, TAL (Tachypleus Amebocyte Lysate) turbidimetric kinetic method was applied to guarantee the accuracy of the test results.

In order to clarify the adsorption characteristics of baicalin and bacterial endotoxin on the surface of activated carbon during the removal process, the present study investigated the activated carbon's function on different concentrations of bacterial endotoxin in aqueous solution of baicalin and the effect on baicalin. The experiments simulated the pyrogenremoving manufacturing techniques of Shuanghuanglian and Qingkailing injections containing baicalin and explored the removal mechanism of activated carbon on bacterial endotoxin. Meanwhile, ultrafiltration (UF) ${ }^{10-13}$ technique was used to explore pyrogen removal for different injections containing baicalin and compare them with activated carbon method. Based on the effect of the removal of bacterial endotoxin and baicalin recovery, we provide a pyrogen removal technique for baicalin aqueous solution and its injections.

\section{EXPERIMENTAL}

Extracts of baicalin were made in laboratory. Shuanghuanglian injections were bought from Harbin Zhenbao Pharmaceutical Co., Ltd. (Lot. No.: 20100970) and Qingkailing Injections were bought from Guangdong Yuanda Pharmaceutical Co., Ltd. (Lot. No.: 1210020).

High performance liquid chromatography (HPLC) was manufactured by Agilent Technologies Co., Ltd. (Mode: 1100) 
with $4.6 \mathrm{~mm} \times 250 \mathrm{~mm}$ Kromasil $\mathrm{C}_{18}$ chromatographic column with VWD detector (280 nm wavelength) and Agilent Chromatography Workstation to determinate the concentration of baicalin. The detection condition is listed below: solvent A, $\mathrm{CH}_{3} \mathrm{OH}$ and solvent $\mathrm{B}, 0.4 \%$ phosphoric acid-water $(\mathrm{A}: \mathrm{B}=$ 47:53). Injection volume: $10 \mu \mathrm{L}$, flow rate: $1.0 \mathrm{~mL} / \mathrm{min}$.

Bacterial endotoxin standard substances were obtained from the National Institute for the Control of Pharmaceutical and Biological Products in China (Lot. No. : 150601-201174, specifications: 160 EU/Amp). Limulus Amebocyte Lysate (LAL) (Lot. No.: 1003090, $\lambda=0.03 \mathrm{EU} / \mathrm{mL}$, specifications: $0.6 \mathrm{~mL} / \mathrm{Amp}$ ) and bacterial endotoxin testing water (Lot. No.: 0910190; specifications: $5 \mathrm{~mL} / \mathrm{Amp}$ ) were manufactured by Zhanjiang Bokang Ocean Creature Co., Ltd. in China. Bacterial endotoxin indicators used for oven verifying (Lot. No.: 120710; specification: 2500 EU/Amp) were bought from Xiamen Limulus Experimental Reagents Co., Ltd. bacterial endotoxin detector was purchased from Tianda Tianfa Technology Co., Ltd. in China (Mode: BET-16M) was used to detect bacterial endotoxin concentration.

Two flat membranes with $5 \mathrm{kDa}$ (Cat. No.: P2B005A05) molecular weight cut off (MWCO) and $10 \mathrm{kDa}$ MWCO (Cat. No.: P2B010A05) manufactured by Millipore Co. in USA were used as the filter media. Injected activated carbon was purchased from activated carbon factory of Hangzhou Timber Plant (Lot. No.: 9708-119, specification: HC-732). The $\mathrm{pH}$ value of baicalin aqueous solution was analyzed by $\mathrm{pH}$ meter (Sartorius, PB-10).

Saturated absorption test of activated carbon for bacterial endotoxin: Three $100 \mathrm{~mL}$ aqueous solutions with $50 \mathrm{EU} / \mathrm{mL}$ bacterial endotoxin were prepared. According the regular proportion of activated carbon in the injection preparation, $0.10,0.50$ and $1 \%$ activated carbon were selected to adsorb the solutions. $0.1,0.5$ and $1 \mathrm{~g}$ activated carbon were added to the three aqueous solutions and then heated to boiling for $15-30 \mathrm{~min}$. After being filtered by pyrogen-free microfiltration membrane, $0.10,0.50$ and $1 \%$ filtrate were obtained. The content of bacterial endotoxin in the filtrate can be tested by the BET method.

Saturated absorption test of activated carbon for baicalin aqueous solution: Proper amount of baicalin powder was used to prepare three $100 \mathrm{~mL}$ aqueous solutions of 5.0 $\mathrm{mg} / \mathrm{mL}$ was adjusted to $\mathrm{pH} 7.5$ using $0.1 \% \mathrm{NaOH}$ solution by $\mathrm{pH}$ meter. Activated carbon with $0.10,0.50$ and $1 \%$ three concentrations were added to the baicalin aqueous solutions using the same methods to adsorb the solutions, thus baicalin filtrate of the three different concentrations of activated carbon were prepared. HPLC was applied to detect the content of baicalin in the filtrate.

Experiment of activated carbon adsorption of baicalin contaminated by bacterial endotoxin: Three $5 \mathrm{mg} / \mathrm{mL}$ baicalin aqueous solutions of $\mathrm{pH} 7.5$ were added bacterial endotoxin to make baicalin stock solutions, which were then added $0.10,0.50$ and $1.00 \%$ activated carbon. We used the same methods to adsorb the three kinds of baicalin aqueous solution with activated carbon and took the filtrate. The removal rate of bacterial endotoxin was calculated according to eqn. 1 and the recovery of baicalin was calculated according to eqn. 2 .

$$
\mathrm{Q}(\%)=\frac{\mathrm{C}_{\mathrm{s}}-\mathrm{C}_{\mathrm{f}}}{\mathrm{C}_{\mathrm{s}}} \times 100 \%
$$

where $\mathrm{Q}$ was the removal rate of bacterial endotoxin, $\mathrm{C}_{\mathrm{s}}$ was the concentration of bacterial endotoxin in stock solution (EU/ $\mathrm{mL}), \mathrm{C}_{\mathrm{f}}$ was the concentration of bacterial endotoxin in filtrate $(\mathrm{EU} / \mathrm{mL})$.

$$
\mathrm{R}(\%)=\frac{\mathrm{C}_{\mathrm{f}}^{\prime}}{\mathrm{C}_{\mathrm{s}}^{\prime}} \times 100 \%
$$

where $\mathrm{R}$ was the recovery of baicalin, $\mathrm{C}_{\mathrm{f}}$ was the concentration of baicalin in filtrate; $\mathrm{C}^{\prime}{ }_{\mathrm{s}}$ was the concentration of baicalin in stock solution.

Injection test: According to the manufacturing technique of Qingkailing and shuanghuanglian injections recorded in China Pharmacopoeia $(\mathrm{CP})^{14}, 0.5 \%$ activated carbon was selected to remove the pyrogen. Addition of bacterial endotoxin was applied to model sudden contamination of bacterial endotoxin in the injections. We also used the same methods to adsorb the two solutions. The removal efficiency of bacterial endotoxin and the recovery of baicalin were calculated by eqns. 1 and 2.

Experiment of bacterial endotoxin in baicalin aqueous solution removed by ultrafiltration: Proper amount of baicalin aqueous solutions of $\mathrm{pH} 7.5$ were filtrated by Millipore membranes $(\mathrm{MWCO}=5 \mathrm{kDa}, 10 \mathrm{kDa}$ ), respectively, after which the filtrate were sampled to calculate the removal efficiency of bacterial endotoxin and the recovery of baicalin using eqns. 1 and 2 above.

Detection of bacterial endotoxin: Bacterial endotoxin test was carried out by turbidity method according to $\mathrm{CP}^{14}$. In brief, a standard substance (160 EU/mL) was diluted to 2.0, $0.5,0.125$ and $0.03125 \mathrm{EU} / \mathrm{mL}$. A $100 \mu \mathrm{L}$ portion of each dilution was mixed with the same volume of a LAL according to the manufacturer's instructions. The reaction mixtures were incubated at $37^{\circ} \mathrm{C}$ and monitored optical density (OD) at the same time. The time to reach a designated turbidity (OD: 0.02) of the reaction mixtures was measured by BET-16M.

Analyses of the series samples were performed using least square method, the relationship between bacterial endotoxin concentration and reaction time was as follows:

$$
\log \mathrm{T}=2.988-0.319 \log \mathrm{C}
$$

where T was reaction time, s. C was bacterial endotoxin concentration, EU/mL. The related coefficient $\mathrm{r}=-0.9929$, therefore, the bacterial endotoxin concentration of stock solution and filtrate was calculated by eqn. 3 .

\section{RESULTS AND DISCUSSION}

Bacterial endotoxin adsorption by activated carbon experiment: After decarburizing by the pyrogen-free microfiltration membrane, with the concentrations of activated carbon increased from $0.10 \%$ to $0.50 \%$ and $1.00 \%$, the bacterial endotoxin contents in the filtrate were decreased from 50.0 to $1.0,0.6$ and $0.3 \mathrm{EU} / \mathrm{mL}$, respectively (Fig. 1). It meant that activated carbon may remove bacterial endotoxin in the solutions by adsorption and the removal efficiency was positively correlated with the dose of activated carbon. 


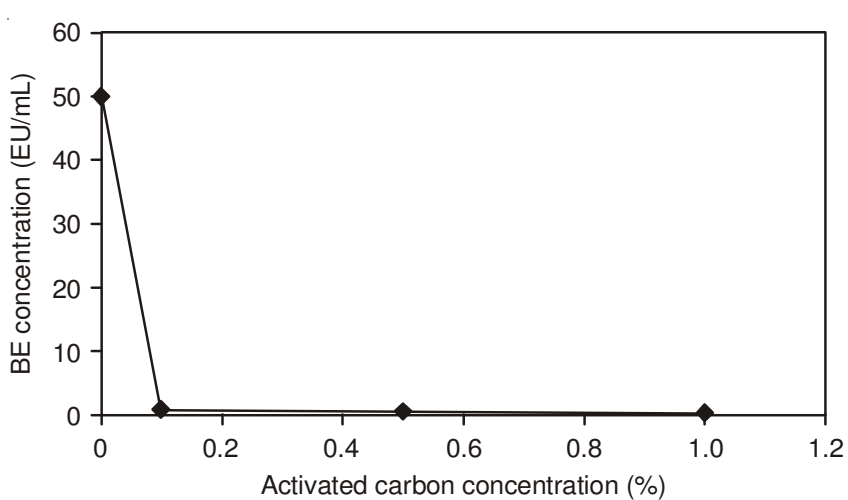

Fig. 1. Bacterial endotoxin adsorption curves with activated carbon

Baicalin adsorption by activated carbon experiment: After using 0.10 and $0.50 \%$ activated carbon, the concentrations of baicalin aqueous solution slightly decreased from the initial 5.0 to 4.5 and $3.8 \mathrm{mg} / \mathrm{mL}$, respectively. Adsorbed by $1 \%$ activated carbon, baicalin concentration was obviously decreased to $2.7 \mathrm{mg} / \mathrm{mL}$ (Fig. 2). It showed that there was a certain adsorption dose-effect correlation between baicalin and activated carbon.

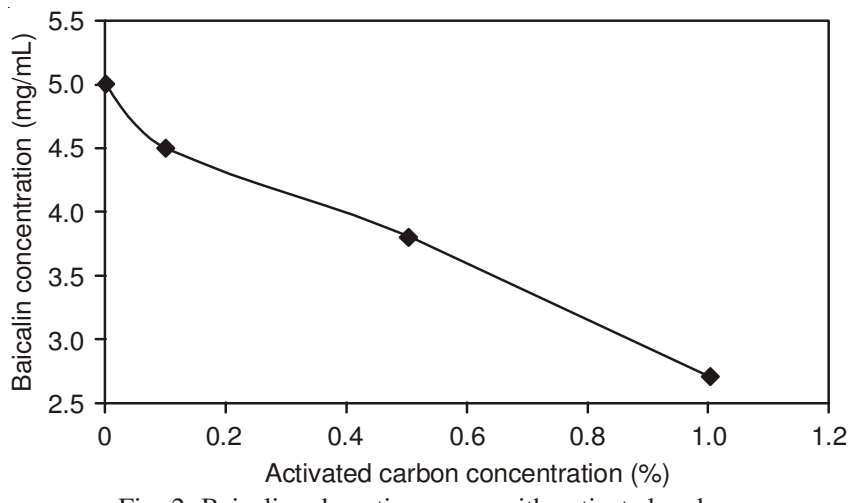

Fig. 2. Baicalin adsorption curve with activated carbon

Adsorption of baicalin contaminated by bacterial endotoxin by activated carbon experiment: Through analyzing the efficiency of activated carbon with different concentrations to remove bacterial endotoxin, it showed that when the concentration of bacterial endotoxin was $11.3 \mathrm{EU} / \mathrm{mL}$, with the increase amount of activated carbon, the efficiency ranged from $67.2 \%$ to $89.5 \%$. However, the baicalin recovery dropped with the increase of activated carbon concentration. When activated carbon concentration was $1.0 \%$, the loss of baicalin reached almost $60 \%$ (Table-1 and Fig. 3a).

\begin{tabular}{|c|c|c|c|c|}
\hline \multicolumn{5}{|c|}{$\begin{array}{c}\text { TABLE-1 } \\
\text { EFFICIENCY OF ACTIVATED CARBON TO } \\
\text { REMOVE BE AND THE BAICALIN RECOVERY }\end{array}$} \\
\hline \multirow{2}{*}{$\begin{array}{l}\text { Activated } \\
\text { carbon } \\
\text { ratio }(\%)\end{array}$} & \multicolumn{2}{|c|}{$\begin{array}{c}\text { Concentration of BE } \\
(\mathrm{EU} / \mathrm{mL})\end{array}$} & \multirow{2}{*}{$\begin{array}{l}\text { BE removal } \\
\text { efficiency } \\
(\%)\end{array}$} & \multirow{2}{*}{$\begin{array}{l}\text { Baicalin } \\
\text { recovery } \\
(\%)\end{array}$} \\
\hline & Stock solution & Filtrate & & \\
\hline 0.10 & \multirow{3}{*}{11.3} & 3.60 & 67.3 & 86.6 \\
\hline 0.50 & & 1.95 & 82.3 & 67.8 \\
\hline 1.00 & & 1.15 & 89.5 & 43.1 \\
\hline 0.10 & \multirow{3}{*}{39.6} & 7.72 & 80.2 & 90.8 \\
\hline 0.50 & & 3.24 & 91.7 & 73.1 \\
\hline 1.00 & & 1.72 & 95.6 & 51.3 \\
\hline
\end{tabular}

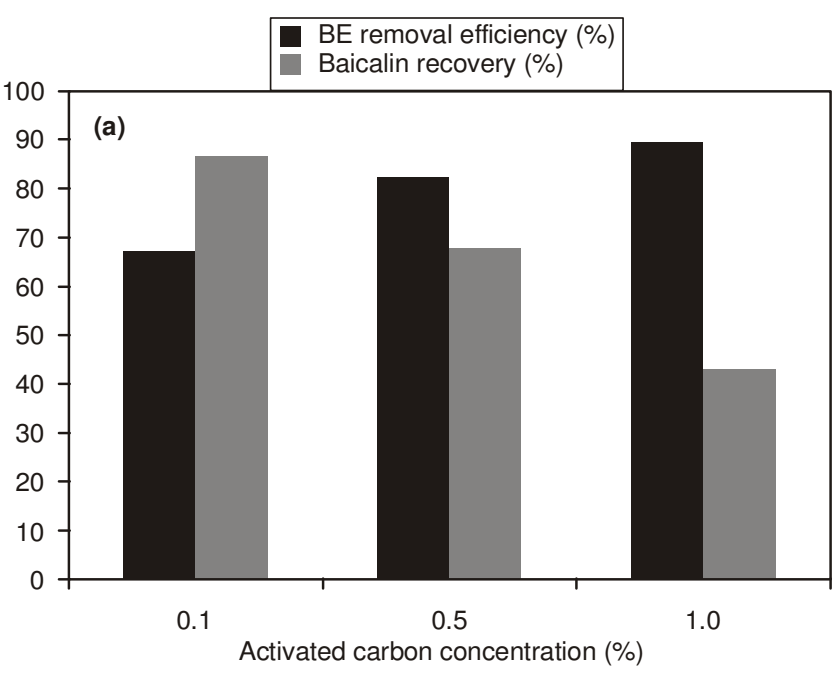

BE removal efficiency (\%) Baicalin recovery $(\%)$

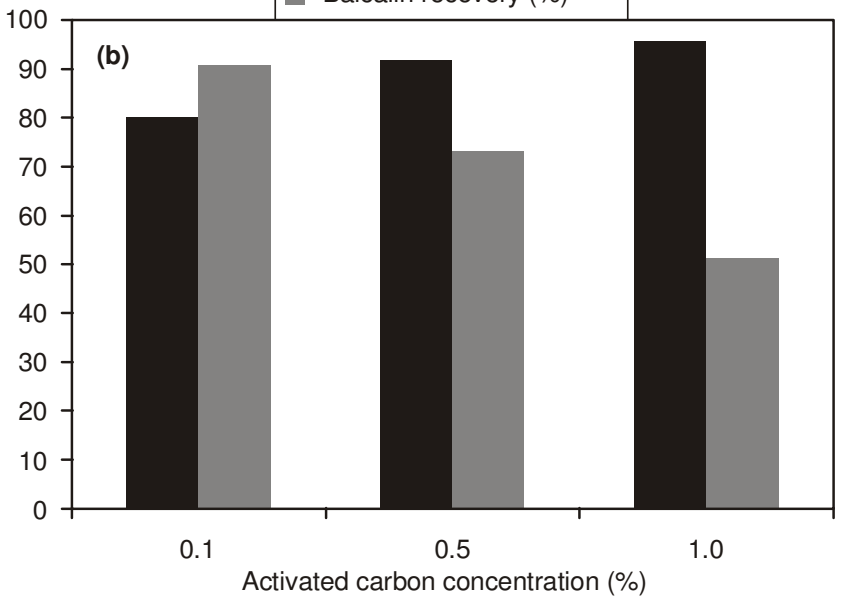

Fig. 3. Bacterial endotoxin removal efficiency and baicalin recovery with activated carbon. (a) bacterial endotoxin concentration was 11.3 $\mathrm{EU} / \mathrm{mL}$; (b) bacterial endotoxin concentration was $39.6 \mathrm{EU} / \mathrm{mL}$

Under severe bacterial endotoxin contamination in the baicalin aqueous solutions, the bacterial endotoxin removal rates of $0.10,0.50$ and $1.00 \%$ activated carbon were 80.2 , 91.7 and $95.6 \%$, respectively. And the corresponding baicalin recovery rose at the same time, ranging from $51.3 \%$ to $90.8 \%$ and (Table-1 and Fig. 3b).

With the increase of activated carbon concentration, the bacterial endotoxin removal rate rose, but the baicalin recovery decreased gradually. When the bacterial endotoxin concentration rose up from 11.3 to $39.6 \mathrm{EU} / \mathrm{mL}$, the baicalin recovery increased correspondingly. It meant that the increase of bacterial endotoxin concentration in the activated carbon particles surface may help activated carbon reduce the baicalin adsorption, that is to say, there was a competitive adsorption between bacterial endotoxin and baicalin on the surface of activated carbon particles. Therefore, when the baicalin aqueous solution was contaminated by bacterial endotoxin, removing bacterial endotoxin by activated carbon adsorption may be difficult to achieve the expected results and may not ensure the safety of the baicalin filtrate.

There is a conjugated system in the baicalin structure. Bacterial endotoxin structure is long-chain. The baicalin and bacterial endotoxin are absorbed together for strong van der 
Waal's force when they are on the surface of the activated carbon particles. Therefore, when baicalin and bacterial endotoxin exist on the surface of the activated carbon particles at the same time, due to competitive adsorption, baicalin loses dramatically and bacterial endotoxin cannot be completely removed.

Injection test: According to the current production process of Shuanghuanglian injection and Qingkailing ionjection, 0.5 $\%$ activated carbon was applied to remove bacterial endotoxin. Results shown in Table-2 found that the contents of bacterial endotoxin in Shuanghuanglian and Qingkailing injection accidentally contaminated by pyrogen were all above $6.0 \mathrm{EU} /$ $\mathrm{mL}$ after the adsorption by activated carbon. The content of bacterial endotoxin in Shuanghuanglian injection was higher than the safe limit value $2.5 \mathrm{EU} / \mathrm{mL}$, while that in Qingkailing injection was in the safe range. Both of the baicalin recovery were less than $80 \%$, significantly. Therefore, during the production process of injections which contain baicalin, when bacterial endotoxin content was low in stock solution, adsorption by activated carbon may be effective and could ensure the safety. However, with moderate or severe pyrogen contamination, using activated carbon cannot completely remove bacterial endotoxin. Consequently, through this study, it is easily found that it may not be suitable for activated carbon to adsorb pyrogen in the injections which contain baicalin.

\begin{tabular}{lcccc}
\multicolumn{5}{c}{ TABLE-2 } \\
EFFICIENCY OF ACTIVATED CARBON TO REMOVE \\
BE AND THE BAICALIN RECOVERY IN INJECTIONS \\
\hline \multirow{4}{*}{$\begin{array}{c}\text { Concentration of BE } \\
\text { Injection }\end{array}$} & $\begin{array}{c}\text { Stock } / \mathrm{mL}) \\
\text { Solution }\end{array}$ & Filtrate & $\begin{array}{c}\text { BE removal } \\
\text { efficiency } \\
(\%)\end{array}$ & $\begin{array}{c}\text { Baicalin } \\
\text { recovery } \\
(\%)\end{array}$ \\
\cline { 2 - 3 } & $\begin{array}{c}\text { Stonn } \\
\text { Shuanghuanglian }\end{array}$ & 6.00 & 86.1 & 75.3 \\
Qingkailing & 45.6 & 7.80 & 82.9 & 79.2 \\
\hline
\end{tabular}

Bacterial endotoxin removal of baicalin aqueous solutions by ultrafiltration: The concentration of additional bacterial endotoxin in baicalin aqueous solution was 70.6 EU/ $\mathrm{mL}$. After filtrated by ultrafiltration membranes whose molecular weight cut off were respectively 5 and $10 \mathrm{kDa}$, the bacterial endotoxin removal rates were all over $99.0 \%$ and the bacterial endotoxin concentrations in the filtrate were below the safe limit value (Table-3). $10 \mathrm{kDa}$ ultrafiltration membrane may ensure the bacterial endotoxin removal rate and effectively maintain baicalin concentration whose loss was less than $6.0 \%$ at the same time.

\begin{tabular}{|c|c|c|c|c|}
\hline & $\begin{array}{l}\text { REMOVAL } \\
\text { F AND THE }\end{array}$ & $\begin{array}{l}\text { BLE-3 } \\
\text { ICIEN } \\
\text { ICALI }\end{array}$ & $\begin{array}{l}\text { OF BE BY } \\
\text { ECOVERY }\end{array}$ & \\
\hline $\begin{array}{c}\text { UF } \\
\text { membrane }\end{array}$ & $\begin{array}{r}\text { Concentrat } \\
(\mathrm{EU} / \mathrm{r}\end{array}$ & of $\mathrm{BE}$ & $\begin{array}{l}\text { BE removal } \\
\text { efficiency }\end{array}$ & $\begin{array}{l}\text { Baicalin } \\
\text { recovery }\end{array}$ \\
\hline$(\mathrm{kDa})$ & Stock solution & Filtrate & $(\%)$ & $(\%)$ \\
\hline 5 & 70.6 & $\begin{array}{l}<\text { Test } \\
\text { limit }\end{array}$ & $\approx 100 \%$ & 52.6 \\
\hline 10 & 70.6 & 0.58 & 99.2 & 94.3 \\
\hline
\end{tabular}

In addition, ultrafiltration technique may not be affected by baicalin content in the filtrating progress because of membrane pore sieving. So ultrafiltration may ensure the pyrogen removal efficiency and the content of baicalin and meet the requirement of injection safety production.

\section{Conclusion}

As the extraction, purification and preparation process of traditional Chinese medicine injections is complicated and long with poor controllability, changes of these environmental factors may lead to over-standard of pyrogen in some batches injections, so that they affect injection safety. If pyrogen contamination suddenly occurs during the production process and bacterial endotoxin content is too high in the stock solution, it is difficult to maintain a safe content range of pyrogen in the injections by applying activated carbon with conventional ratio.

Due to the limitations of saturated and competitive adsorption, when we eliminate pyrogen in the solutions containing baicalin and similar structures by adsorption with activated carbon, it may not ensure the removal efficiency. However, according to differences in molecular weight of drug ingredients and pyrogen, ultrafiltration technique can overcome the above limitations and eliminate pyrogen in the injections containing baicalin. Hence, ultrafiltration has its unique advantages by membrane pore sieving technology.

\section{ACKNOWLEDGEMENTS}

The authors expressed their thanks to Higher Education Science and Technology Support Project of Jiangsu Province, China (Project No.: 12KJB36009) and the State Key Laboratory of New-tech for Chinese Medicine Pharmaceutical Process of China (Project No.: SKL2010Z0201).

\section{REFERENCES}

1. M. Nagaki, R.D. Hughes, J.Y. Lau and R. Williams, Int. J. Artif. Organs., 14, 43 (1991)

2. G. Reiter, D. Falkenhagen, M. Siam, W. Gollneritsch, D. Baurecht and U.P. Fringeli, Langmuir, 18, 5761 (2002).

3. P.O. Magalhães, A.M. Lopes, P.G. Mazzola, C. Rangel-Yagui, T.C.V. Penna and A.J. Pessoa, J. Pharm. Pharmaceut. Sci., 10, 388 (2007).

4. S.E. Grisman and R.B. Hornick, Proc. Soc. Exp. Biol. Med., 131, 1154 (1969).

5. S. Sasaki, Bull. Tokyo Dent. Coll., 20, 159 (1979).

6. S.A. Olenchock, S.W. Lenhart and J.C. Mull, J. Toxicol. Environ. Health, 9, 339 (1982).

7. J.L. Ding and B.Ho, Trends Biotechnol., 19, 277 (2001).

8. M. Nagaki, R.D. Hughis, H.N. Kean, J.Y.N. Lau and R. Williams, Circ. Shock, 38, 182 (1992).

9. S.K. Sharma, Biotechnol. Appl. Biochem., 8, 5 (1986).

10. R. Schindler and C.A. Dinarello, J. Immunol. Methods, 116,159 (1989).

11. M. Fischbach, E. Heinrich, P. Desprez and R. Duringer, Nephron, 66, 117 (1994).

12. Y. Sawada, R. Fujii, I. Igami, A. Kawai, T. Kamiki and M. Niwa, Appl. Environ. Microbiol., 51, 813 (1986).

13. J.H. Li, Y.G. Shao, Z.A. Chen, R.Z. Cong, J.D. Wang and X.L. Liu, J. Chromatogr. B, 791, 55 (2003).

14. The Chinese Pharmacopoeia Commission, Ministry of Health of the People's Republic of China, China Pharmacopeia (2010). 